\title{
Effect of horizontal heterogeneity on productivity of cyclic superheated steam stimulation horizontal wells: numerical analysis
}

\author{
Fengrui Sun ${ }^{1,2,3} \cdot$ Yuedong Yao ${ }^{1,2,3} \cdot$ Guozhen $\mathrm{Li}^{3}$
}

Received: 5 November 2018 / Accepted: 16 February 2019 / Published online: 23 February 2019

(c) The Author(s) 2019

\begin{abstract}
In recent decades, horizontal well has been widely used for heavy oil recovery. Besides, new developed thermal carriers, such as multi-component thermal fluid and superheated steam, have been proved effective in some oil fields. However, when the length of the horizontal wellbore is quite long or when the reservoir is of serious heterogeneity, the steam fingering phenomenon can be serious. The existence of horizontal heterogeneity leads to the low recovery efficiency and serious steam fingering phenomenon. In this paper, a numerical model is built to study the effect of horizontal heterogeneity on the productivity of production well during the cyclic superheated steam stimulation process. Simulation results show that (a) the effect of permeability distribution pattern in the horizontal direction on the recovery degree can be neglected. This may be caused by the infinity of fluid fluidity in the wellbores. (b) The effect of permeability distribution pattern in the horizontal direction on the cyclic oil production can be neglected. (c) The temperature is the highest in the high permeability section, while the temperature is the lowest in the low permeability section. However, given the fact that the wellbore conductivity is assumed to be infinity, the effect of permeability distribution pattern on the performance of the production well can be neglected.
\end{abstract}

Keywords Heavy oil $\cdot$ Horizontal well $\cdot$ Cyclic superheated steam stimulation $\cdot$ Horizontal heterogeneity $\cdot$ Permeability distribution pattern $\cdot$ Numerical modeling

\section{Introduction}

Unconventional resources becomes more important in present petroleum industry (Tang and Wu 2018; Xiong et al. 2018, 2017b, 2019). The heat and mass transfer process that happens in an engineering case can be a study topic for engineers (Sheikholeslami 2018; Fengrui et al. 2019a,

Fengrui Sun

13126682711@163.com

$\triangle$ Yuedong Yao

1181890005@qq.com

$\triangle$ Guozhen Li

1174107928@qq.com

1 State Key Laboratory of Petroleum Resources and Prospecting, China University of Petroleum, Beijing 102249, Beijing, People's Republic of China

2 College of Petroleum Engineering, China University of Petroleum, Beijing 102249, Beijing, People's Republic of China

3 China University of Petroleum, Beijing 102249, Beijing, People's Republic of China 2020a, b; Xiong et al. 2017a; Huang 2016, 2017; Feng et al. 2018; Fengrui et al. 2019c, d, 2020c, d; Sun et al. 2017a, b, c, d; Xindi and Baojun 2017; Yu et al. 2019; Sun et al. 2019, Fengrui et al. 2019b). The mass transfer can be found in nearly every aspect in the petroleum industry (Meng et al. 2018; Fengrui et al. 2019e, f, g; Sun et al. 2017e, f, g, h; Jichao et al. 2018), while the heat transfer always happens during the thermal recovery process of heavy oil (Zhanghua et al. 2015; Huang et al. 2018a, b, c; Sun et al. 2018a, b, c; Mohammad et al. 2018; Ezeuko and Gates 2018). In this paper, the thermal recovery process of cyclic superheated steam stimulation using a horizontal well is studied.

When it comes to the enhanced oil recovery, horizontal well has been proved effective in increasing contact area ( $\mathrm{Yi}$ et al. 2018; Yang et al. 2018; Sun et al. 2018d, e, f). On the other hand, newly developed thermal fluid, such as multicomponent thermal fluid and superheated steam, have been proved successful in increasing oil recovery efficiency (Sun et al. 2018g, h, i, j, k, l, m, n, o, p, q, r, s, t, u, v; Fengrui et al. 2018). However, it comes with the difficulty that the steam channeling may become more serious when there is 
a long horizontal wellbore or the horizontal heterogeneity is serious.

Given the fact the heterogeneity always happens along the horizontal well, which may have an influence on the performance of the production well. As a result, we conducted a numerical study to investigate the effect of horizontal heterogeneity on productivity of cyclic superheated steam stimulation horizontal wells using a numerical model.

Effect of different combination of permeability in the horizontal direction is studied. First, a numerical model is established using the commercial numerical simulation software. Then, different combinations of permeability in the horizontal direction are input into the model. The effect of different combinations of permeability in the horizontal direction on the productivity of the horizontal well is studied.

\section{Numerical model}

Corner grid is used to build the structure of the model. The reservoir size is $450 \times 200 \times 20 \mathrm{~m}$. The grid size is $10 \times 10 \times 2 \mathrm{~m}$. The length of the horizontal well is $250 \mathrm{~m}$.

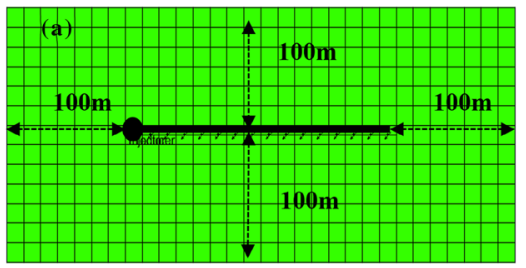

I-J Profile

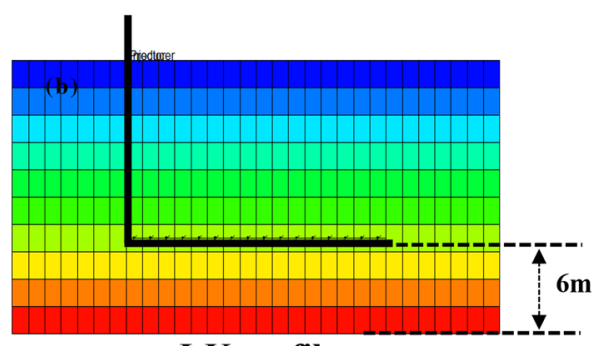

I-K profile

Fig. 1 The I-J and I-K profiles of the numerical model
The location of the wellbore in the reservoir is shown in Fig. 1 below.

Some basic parameters used for calculation are shown in Table 1 below. Note that the permeability in the horizontal direction is $1000 \mathrm{mD}$.

Based on the above model, the permeability along the horizontal direction is modified to study the effect of horizontal heterogeneity on the performance of the production well. The permeability distribution pattern is shown in Fig. 2 below.

Totally nine permeability distribution patterns are studied in this paper. The detailed permeability distribution patterns are shown in Fig. 3 below. The permeability level has been classified as high, medium and low. The high level is equal to $1700 \mathrm{mD}$. The medium level is equal to $1000 \mathrm{mD}$. The low level is equal to $300 \mathrm{mD}$.

\section{Results and discussion}

Based on the above model, these non-permeability distribution patterns are input into the model. The calculated results are shown below.

Figure 4 shows the effect of permeability distribution pattern in the horizontal direction on the recovery degree. It is observed that the curves of different permeability

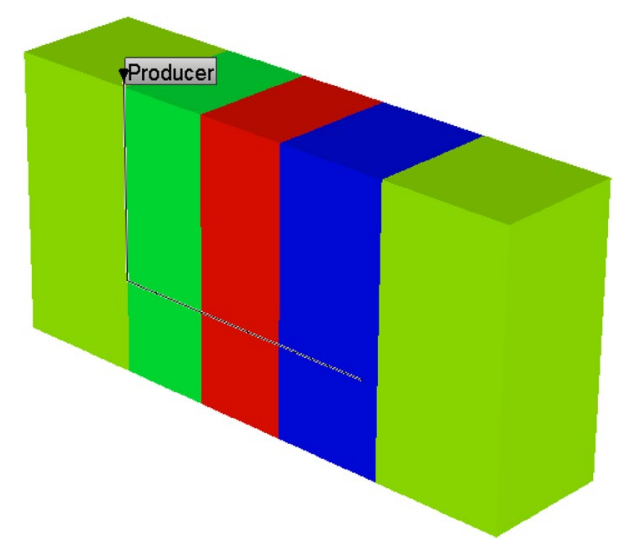

Fig. 2 The permeability distribution pattern along the horizontal wellbore
Table 1 Basic parameters of the numerical model

\begin{tabular}{lllr}
\hline Physical parameter & Value & Physical parameter & Value \\
\hline Reservoir size, $\mathrm{m}$ & $450 \times 200 \times 20$ & Superheated steam temperature, ${ }^{\circ} \mathrm{C}$ & 321 \\
Grid size, $\mathrm{m}$ & $10 \times 10 \times 2$ & Soak time, day & 15 \\
Buried depth, $\mathrm{m}$ & 320 & Injection pressure, $\mathrm{kPa}$ & 5100 \\
Porosity, dimensionless & 33.8 & Length of the horizontal well, $\mathrm{m}$ & 250 \\
Rock compression coefficient, $^{\mathrm{KPa}^{-1}}$ & $3.58 \times 10^{-5}$ & Reservoir temperature, ${ }^{\circ} \mathrm{C}$ & 16 \\
\hline
\end{tabular}



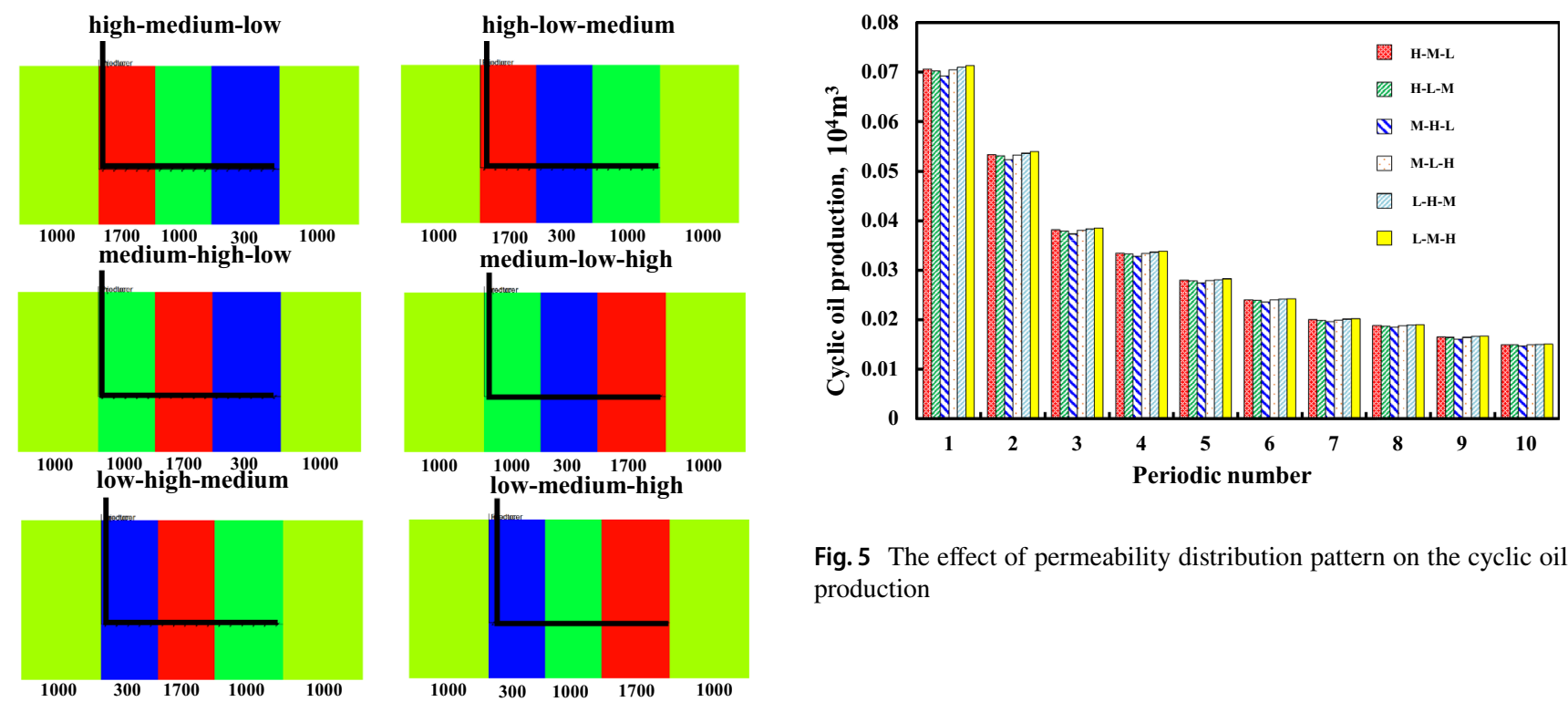

Fig. 3 The detailed permeability distribution pattern along the horizontal wellbore

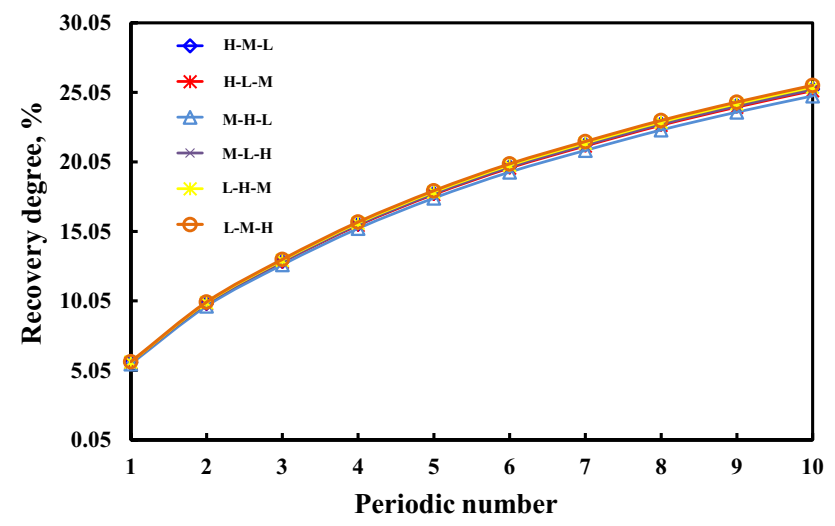

close to each other under all cycles. The effect of permeability distribution pattern in the horizontal direction on the cyclic oil production can be neglected.

Figure 6 shows the temperature fields under various permeability distribution patterns. It is observed that the temperature is the highest in the high permeability section, while the temperature is the lowest in the low permeability section. However, given the fact that the wellbore conductivity is assumed to be infinity, the effect of permeability distribution pattern on the performance of the production well can be neglected.

\section{Conclusion}

The horizontal heterogeneity is always the issue that bothers the practical engineers. The existence of horizontal

Fig. 4 The effect of permeability distribution pattern on the recovery degree heterogeneity leads to the low recovery efficiency and serious steam fingering phenomenon. In this paper, a numerical model is built to study the effect of horizontal heterogeneity on the productivity of production well during the cyclic superheated steam stimulation process. Some meaningful conclusions are listed below:

distribution patterns are close to each other. The effect of permeability distribution pattern in the horizontal direction on the recovery degree can be neglected. This may be caused by the infinity of fluid fluidity in the wellbores.

Figure 5 shows the effect of permeability distribution pattern in the horizontal direction on the cyclic oil production. It is observed that the cyclic oil production is

a. The effect of permeability distribution pattern in the horizontal direction on the recovery degree can be neglected. This may be caused by the infinity of fluid fluidity in the wellbores.

b. The effect of permeability distribution pattern in the horizontal direction on the cyclic oil production can be neglected.

c. The temperature is the highest in the high permeability section, while the temperature is the lowest in the 


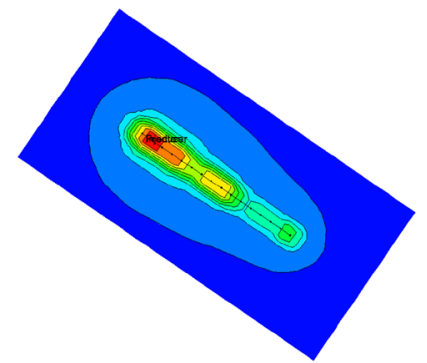

H-M-L

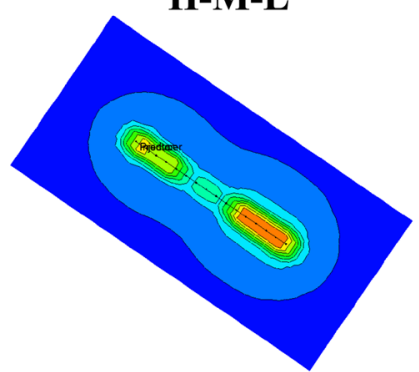

M-L-H

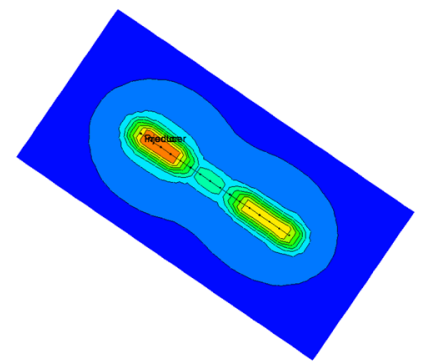

H-L-M

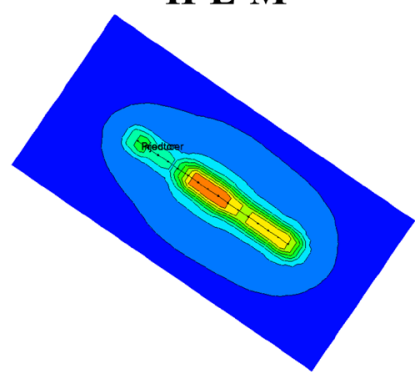

L-H-M

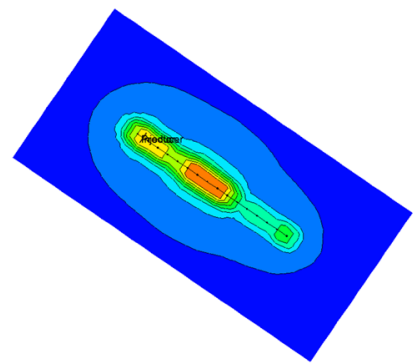

Temperature, ${ }^{\circ} \mathrm{C}$

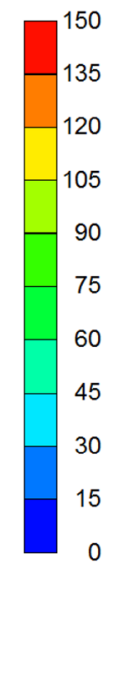

L-M-H

Fig. 6 The temperature fields under various permeability distribution patterns

low permeability section. However, given the fact that the wellbore conductivity is assumed to be infinity, the effect of permeability distribution pattern on the performance of the production well can be neglected.

Acknowledgements The research was supported by National Science and Technology Major Projects of China (No. 2016ZX05042, No. 2017ZX05039 and 2016ZX05039) and the National Natural Science Foundation Projects of China (No. 51504269, No. 51490654 and No. 40974055). The authors also acknowledge Science Foundation of China University of Petroleum, Beijing (No.C201605), the National Basic Research Program of China (2015CB250900), the Program for New Century Excellent Talents in University (Grant no. NCET-131030) to support part of this work.

Open Access This article is distributed under the terms of the Creative Commons Attribution 4.0 International License (http://creativeco mmons.org/licenses/by/4.0/), which permits unrestricted use, distribution, and reproduction in any medium, provided you give appropriate credit to the original author(s) and the source, provide a link to the Creative Commons license, and indicate if changes were made.

\section{References}

Ezeuko CC, Gates ID (2018) Thermal oil recovery from fractured reservoirs: energy and emissions intensities. Energy 155:29-34

Feng D, Li XF, Wang XZ, Li J, Zhang T, Sun Z, He MX, Liu Q, Qin JZ, Han S, Hu JC (2018) Anomalous capillary rise under nanoconfinement: a view of molecular kinetic theory. Langmuir 34(26):7714-7725

Fengrui S, Yuedong Y, Guozhen L (2018) Comments on: the flow and heat transfer characteristics of compressed air in high-pressure air injection wells [Arabian Journal of Geosciences (2018) 11: 519]. Arab JGeosci 11(20):631

Fengrui S, Yuedong Y, Guozhen L, Xiangfang L (2019a) Effect of critical thickness on nanoconfined water fluidity: review, communication, and inspiration. J Pet Explor Prod Technol. https:// doi.org/10.1007/s13202-018-0540-6

Fengrui S, Yuedong Y, Guozhen L (2019b) Comments on heat and mass transfer characteristics of steam in a horizontal wellbore with multi-point injection technique considering wellbore stock liquid [International Journal of Heat and Mass Transfer 127 (2018) 949-958]. Int J Heat Mass Transf 132:1319-1321

Fengrui S, Yuedong Y, Guozhen L, Xiangfang L (2019c) Transport zones of oil confined in lipophilic nanopores: a technical note. Arabian J Geosci 12(4):136

Fengrui S, Yuedong Y, Guozhen L, Xiangfang L (2019d) A slip-flow model for multi-component shale gas transport in organic nanopores. Arabian J Geosci 12(5):143

Fengrui S, Yuedong Y, Xiangfang L, Guozhen L (2019e) An analytical equation for oil transport in nanopores of oil shale considering viscosity distribution. J Pet Explor Prod Technol. https://doi. org/10.1007/s13202-018-0486-8

Fengrui S, Yuedong Y, Guozhen L (2019f) New analytical equations for productivity estimation of the cyclic $\mathrm{CO}_{2}$-assisted steam stimulation process considering the non-Newtonian percolation characteristics. J Pet Explor Prod Technol. https://doi.org/10.1007/ s13202-018-0518-4

Fengrui S, Yuedong Y, Guozhen L, Xiangfang L (2019g) Effect of physical heating on productivity of cyclic superheated steam stimulation wells. J Pet Explor Prod Technol. https://doi.org/10.1007/ s13202-018-0527-3

Fengrui S, Yuedong Y, Guozhen L (2020a) Effect of bottom water on performance of cyclic superheated steam stimulation using a horizontal well. J Pet Explor Prod Technol. https://doi.org/10.1007/ s13202-019-0625-x

Fengrui S, Yuedong Y, Guozhen L (2020b) Slight insights and perspectives of future heavy oil recovery. J Pet Explor Prod Technol. https ://doi.org/10.1007/s13202-019-0615-z 
Fengrui S, Yuedong Y, Guozhen L, Dong M (2020c) Transport behaviors of real gas mixture through nanopores of shale reservoir. J Pet Sci Eng. https://doi.org/10.1016/j.petrol.2018.12.058

Fengrui S, Yuedong Y, Guozhen L, Wenyuan L (2020d) A numerical model for wet steam circulating in horizontal wellbores during starting stage of the steam-assisted-gravity-drainage process. Heat Mass Transf. https://doi.org/10.1007/s00231-019-02564-7

Huang S, Xiong Hao, Wei S et al (2016) Physical simulation of the interlayer effect on SAGD production in MacKay river oil sands. Fuel 183:373-385. https://doi.org/10.1016/j.fuel.2016.06.104

Huang S, Xiong H, Kuiqian MA et al (2017) A mathematical model for productivity prediction of SAGD process considering non-uniform steam distribution. J Chin Univ Pet (Edition of Natural Science) 41(4):107-115. https://doi.org/10.3969/j. issn.1673-5005.2017.04.014

Huang SJ, Cao M, Cheng LS (2018a) Experimental study on the mechanism of enhanced oil recovery by multi-thermal fluid in offshore heavy oil. Int J Heat Mass Transf 122:1074-1084

Huang SJ, Cao M, Xia Y, Chen X, Yang ML (2018b) Heat and mass transfer characteristics of steam in a horizontal wellbore with multi-point injection technique considering wellbore stock liquid. Int J Heat Mass Transf 127(Part B):949-958

Huang SJ, Cao M, Cheng LS (2018c) Experimental study on aquathermolysis of different viscosity heavy oil with superheated steam. Energy Fuels 32(4):4850-4858

Jichao H, Changdong Y, Jixiang H (2018) Transient pressure analysis of horizontal well with nonorthogonal transverse fractures and drainage volume characterization using fast marching method. J Nat Gas Sci Eng 54:110-119

Meng Y, Li X, Jiang M et al (2018) Experimental research on three dimensional flow characteristics of multiple horizontal fractures utilizing an innovative experiment apparatus. Arab J Geosci 11:243. https://doi.org/10.1007/s12517-018-3589-0

Mohammad IM, Murtada AE, Salim A, Hossain ME (2018) Modeling of temperature distribution and oil displacement during thermal recovery in porous media: a critical review. Fuel 226:423-440

Sheikholeslami M (2018) Finite element method for PCM solidification in existence of $\mathrm{CuO}$ nanoparticles. J Mol Liq 265:347-355

Sun F, Yao Y, Li X, Yu P, Ding G, Zou M (2017a) The flow and heat transfer characteristics of superheated steam in offshore wells and analysis of superheated steam performance. Comput Chem Eng 100:80-93

Sun F, Yao Y, Chen M, Li X, Zhao L, Meng Y, Sun Z, Zhang T, Feng D (2017b) Performance analysis of superheated steam injection for heavy oil recovery and modeling of wellbore heat efficiency. Energy 125:795-804

Sun F, Yao Y, Li X, Yu P, Zhao L, Zhang Y (2017c) A numerical approach for obtaining type curves of superheated multi-component thermal fluid flow in concentric dual-tubing wells. Int J Heat Mass Transf 111:41-53

Sun F, Yao Y, Li X, Zhao L (2017d) Type curve analysis of superheated steam flow in offshore horizontal wells. Int J Heat Mass Transf 113:850-860

Sun F, Yao Y, Li X, Zhao L, Ding G, Zhang X (2017e) The mass and heat transfer characteristics of superheated steam coupled with non-condensing gases in perforated horizontal wellbores. J Pet Sci Eng 156:460-467

Sun F, Yao Y, Li X, Tian J, Zhu G, Chen Z (2017f) The flow and heat transfer characteristics of superheated steam in concentric dualtubing wells. Int J Heat Mass Transf 115:1099-1108

Sun F, Yao Y, Li X, Li H, Chen G, Sun Z (2017g) A numerical study on the non-isothermal flow characteristics of superheated steam in ground pipelines and vertical wellbores. J Pet Sci Eng 159:68-75
Sun F, Yao Y, Li X (2017h) Effect of gaseous $\mathrm{CO}_{2}$ on superheated steam flow in wells. Eng Sci Technol Int J 20(6):1579-1585

Sun F, Yao Y, Li X (2018a) The heat and mass transfer characteristics of superheated steam coupled with non-condensing gases in horizontal wells with multi-point injection technique. Energy 143:995-1005

Sun F, Yao Y, Li X, Li G, Chen Z, Chang Y, Cao M, Han S, Chaohui L, Feng D, Sun Z (2018b) Effect of flowing seawater on supercritical $\mathrm{CO}_{2}$ - superheated water mixture flow in an offshore oil well considering the distribution of heat generated by the work of friction. J Pet Sci Eng 162:460-468

Sun F, Yao Y, Li X, Li G, Miao Y, Han S, Chen Z (2018c) Flow simulation of the mixture system of supercritical $\mathrm{CO}_{2} \&$ superheated steam in toe-point injection horizontal wellbores. J Pet Sci Eng 163:199-210

Sun F, Yao Y, Li X, Li G, Sun Z (2018d) A numerical model for predicting distributions of pressure and temperature of superheated steam in multi-point injection horizontal wells. Int J Heat Mass Transf 121:282-289

Sun F, Yao Y, Li X, Li G, Huang L, Liu H, Chen Z, Liu Q, Liu W, Cao M, Han S (2018e) Exploitation of heavy oil by supercritical $\mathrm{CO}_{2}$ : effect analysis of supercritical $\mathrm{CO}_{2}$ on $\mathrm{H}_{2} \mathrm{O}$ at superheated state in integral joint tubing and annuli. Greenh Gases Sci Technol 8(3):557-569

Sun F, Yao Y, Li X, Li G, Liu Q, Han S, Zhou Y (2018f) Effect of friction work on key parameters of steam at different state in toepoint injection horizontal wellbores. J Pet Sci Eng 164:655-662

Sun F, Yao Y, Li X, Li G, Han S, Liu Q, Liu W (2018g) Type curve analysis of multi-phase flow of multi-component thermal fluid in toe-point injection horizontal wells considering phase change. J Pet Sci Eng 165:557-566

Sun F, Yao Y, Li G, Li X, Chen M, Chen G, Zhang T (2018h) Analysis of superheated steam performance in offshore concentric dualtubing wells. J Pet Sci Eng 166: 984-999

Sun F, Yao Y, Li G, Li X, Lu C, Chen Z (2018i) A model for predicting thermophysical properties of water at supercritical state in offshore CDTW. Measurement 124:241-251

Sun F, Yao Y, Li G, Li X, Zhang T, Lu C, Liu W (2018j) An improved two-phase model for saturated steam flow in multi-point injection horizontal wells under steady-state injection condition. J Pet Sci Eng 167:844-856

Sun F, Yao Y, Li G, Li X (2018k) Geothermal energy extraction in $\mathrm{CO}_{2}$ rich basin using abandoned horizontal wells. Energy 158:760-773

Sun F, Yao Y, Li G, Li X, Li Q, Yang J, Wu J (20181) A coupled model for $\mathrm{CO}_{2}$ \& superheated steam flow in full-length concentric dualtube horizontal wells to predict the thermophysical properties of $\mathrm{CO}_{2}$ \& superheated steam mixture considering condensation. $\mathrm{J}$ Pet Sci Eng 170:151-165

Sun F, Yao Y, Li G, Li X (2018m) Performance of geothermal energy extraction in a horizontal well by using $\mathrm{CO}_{2}$ as the working fluid. Energy Convers Manag 171:1529-1539

Sun F, Yao Y, Li X (2018n) The heat and mass transfer characteristics of superheated steam in horizontal wells with toe-point injection technique. J Pet Explor Prod Technol 8(4):1295-1302

Sun F, Yao Y, Li X, Li G (20180) A brief communication on the effect of seawater on water flow in offshore wells at supercritical state. J Pet Explor Prod Technol 8(4):1587-1596

Sun F, Yao Y, Li X (2018p) Effect analysis of non-condensable gases on superheated steam flow in vertical single-tubing steam injection pipes based on the real gas equation of state and the transient heat transfer model in formation. J Pet Explor Prod Technol 8(4):1325-1330

Sun F, Yao Y, Li X (2018q) Numerical simulation of superheated steam flow in dual-tubing wells. J Pet Explor Prod Technol 8(3):925-937

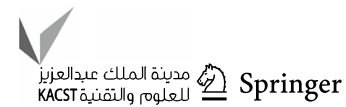


Sun F, Yao Y, Li G, Li X (2018r) Geothermal energy development by circulating $\mathrm{CO}_{2}$ in a U-shaped closed loop geothermal system. Energy Convers Manag 174:971-982

Sun F, Yao Y, Li G, Zhao L, Liu H, Li X (2018s) Water performance in toe-point injection wellbores at supercritical state. In: SPE Trinidad and Tobago section energy resources conference, SPE191151-MS, 25-26 June 2018 in Port of Spain, Trinidad and Tobago. https://doi.org/10.2118/191151-MS

Sun F, Yao Y, Li G, Li X (2018t) Numerical simulation of supercriticalwater flow in concentric-dual-tubing wells. SPE J 23(6):21882201. https://doi.org/10.2118/191363-PA

Sun F, Yao Y, Li G, Li X, Sun J (2018u) Comparison of steam front shape during steam flooding process under varying steam state condition: numerical analysis. In: Abu Dhabi international petroleum exhibition and conference, SPE-192996-MS, 12-15 November, 2018, Abu Dhabi, UAE

Sun F, Yao Y, Li G, Qu S, Zhang S, Shi Y, Xu Z, Li X (2018v) Effect of pressure and temperature of steam in parallel vertical injection wells on productivity of a horizontal well during the SAGD process: a numerical case study. In: SPE international heavy oil conference \& exhibition, SPE-193659-MS, 10-12 December 2018 in Kuwait City, Kuwait

Sun F, Yao Y, Li G, Zhang S, Xu Z, Shi Y, Li X (2019) A slip-flow model for oil transport in organic nanopores. J Pet Sci Eng 172:139-148

Tang J, Wu K (2018) A 3-D model for simulation of weak interface slippage for fracture height containment in shale reservoirs. Int J Solids Struct 144-145:248-264. https://doi.org/10.1016/j.ijsol str.2018.05.007

Xiong H, Huang S, Liu H, Cheng L, Ma K, Huang Q (2017a) A novel optimization of SAGD to enhance oil recovery - The effects of pressure difference. In: 19th European Symposium on Improved Oil Recovery, Norway, Stavanger, 24-27 April 2017. https://doi. org/10.3997/2214-4609.201700250
Xiong H, Huang S, Liu H, Cheng L, Li J, Xiao P (2017b) A novel model to investigate the effects of injector-producer pressure difference on SAGD for bitumen recovery. Int J Oil Gas Coal Technol 16(3):217-235

Xiong H, Huang S, Devegowda D et al (2018) Simulation and modeling of pressure difference on steam chamber and production performance[C]. Society of Petroleum Engineers, California, USA, 22-27 April 2018. https://doi.org/10.2118/190107-MS

Xiong H, Huang S, Devegowda D, Liu H, Li H, Padgett Z (2019) Influence of pressure difference between reservoir and production well on steam chamber propagation and reservoir production performance. SPE J. https://doi.org/10.2118/190107-PA

Xindi SUN, Baojun BAI (2017) Comprehensive review of water shutoff methods for horizontal wells. Pet Explor Dev 44(6):1022-1029

Yang L, Tianshou M, Ping C, Chuan Y (2018) Method and apparatus for monitoring of downhole dynamic drag and torque of drillstring in horizontal wells. J Pet Sci Eng 164:320-332

Yi D, Pingya L, Xiangjun L, Lixi L (2018) Wellbore stability model for horizontal wells in shale formations with multiple planes of weakness. J Nat Gas Sci Eng 52:334-347

Yu H, Li Q, Sun F (2019) Numerical simulation of $\mathrm{CO}_{2}$ circulating in a retrofitted geothermal well. J Pet Sci Eng 172:217-227

Zhanghua L, Qiang Z, Tiejun L, Fuhui W (2015) Experimental and numerical study of drill string dynamics in gas drilling of horizontal wells. J Nat Gas Sci Eng 27(Part 3):1412-1420

Publisher's note Springer Nature remains neutral with regard to jurisdictional claims in published maps and institutional affiliations. 